\title{
Neuroprotective Effect of Fagopyrum dibotrys Extract against Alzheimer's Disease
}

\author{
Chen Liang, ${ }^{1}$ Jian-Ping Yuan, ${ }^{2}$ Tao Ding, ${ }^{1}$ Lv Yan, ${ }^{2}$ Lu Ling, \\ Xin-Fu Zhou, ${ }^{1,3}$ and Yue-Qin Zeng' \\ ${ }^{1}$ Key Laboratory of Stem Cells and Regenerative Medicine, Institute of Molecular and Clinical Medicine, \\ Kunming Medical University, Kunming, China \\ ${ }^{2}$ Department of Pharmacy, First People's Hospital of Qujin, Qujin, China \\ ${ }^{3}$ School of Pharmacy and Medical Sciences, Sansom Institute, University of South Australia, Adelaide, SA, Australia \\ Correspondence should be addressed to Yue-Qin Zeng; z_yueqin@hotmail.com
}

Received 20 November 2016; Revised 12 February 2017; Accepted 16 March 2017; Published 20 April 2017

Academic Editor: Evan P. Cherniack

Copyright (C) 2017 Chen Liang et al. This is an open access article distributed under the Creative Commons Attribution License, which permits unrestricted use, distribution, and reproduction in any medium, provided the original work is properly cited.

\begin{abstract}
Accumulated evidence suggests that polyphenolic antioxidants present in herbs play important roles in prevention of AD; the molecular mechanisms behind neuroprotective actions rely on the phenols through different effects on the amyloid-aggregation pathway. Fagopyrum dibotrys is a traditional herbal medicine which contains high quantity phenols. In present study, we investigate the beneficial pharmacological actions of Fagopyrum dibotrys extract in the APP/PS1 transgenic mouse mode; meanwhile, effects of the FDE on the fibrillation and cytotoxicity of $\mathrm{A} \beta$ peptide were evaluated in vitro. After 9-month treatment, FDE exhibited multifunctional properties on $\mathrm{A} \beta$-related pathologies, which cleaned $\mathrm{A} \beta$ deposits in the brain and decreased $\mathrm{A} \beta$ burden in the plasma, inhibited microhaemorrhage, and reduced reactive microglia in APP/PS1 transgenic mice and also promoted A $\beta$ fibrils disaggregation and inhibited neurotoxicity induced by $\mathrm{A} \beta$ in SH-SY5Y cells. These results highlighted that FDE is an AD type pathology modulator with therapeutic potential against $\mathrm{AD}$.
\end{abstract}

\section{Introduction}

Alzheimer disease (AD) is progressive and neurodegenerative disorder disease among the elderly, characterized by progressive loss of memory and cognition [1]. Histopathological hallmarks of $\mathrm{AD}$ include deposition of $\beta$-amyloid plaques and formation of neurofibrillary tangles, intracellular neurofibrillary tangles, reactive microgliosis, and astrogliosis [2]. Although several compounds undergoing research appeared to be protective and therapeutic effects on $\mathrm{AD}$ model, none of these drugs was able to stop or reverse the course in patients with AD.

Fagopyrum dibotrys (D. Don.) Hara is an erect perennial herb with clusters of small pinkish or white flowers and edible triangular seeds, growing mainly in China, India, Vietnam, Thailand, and Nepal [3, 4]. In China, its rhizome was regarded as folk medicine for the treatment of lung diseases, inflammation, dysentery, traumatic injuries and rheumatism [5].
The Fagopyrum dibotrys extract (FDE) was characterized by the abundance of proanthocyanidins, hecogenin, ferulic acid, catechin, gallic acid, epicatechin, and so on. Some polyphenol compounds such as ferulic acid and epicatechin have been reported to exhibit neuroprotective properties including therapeutic action in $\mathrm{AD}[6,7]$ that may be attributed to these polyphenol metabolites which are able to cross the $\mathrm{BBB}$ and to penetrate and accumulate in the brain at pharmacologically relevant sub $\mu \mathrm{M}$ to $\mu \mathrm{M}$ concentration [8], tightly controlling the influx in the brain of metabolites and nutrients as well as of drugs [9]. The total polyphenols content in Fagopyrum dibotrys is about $37.7 \%$ according to the test report provided by R\&D department of Qujin Gelikang Science and Technological Co. Ltd. But up till now no studies have been carried out to show the effect of total polyphenols content in Fagopyrum dibotrys on the modulation of $\mathrm{A} \beta$ related pathologies. Here, we report that FDE can influence the $\mathrm{A} \beta$ aggregation and $\mathrm{A} \beta$-related pathology process. 


\section{Materials and Methods}

2.1. Preparation of Fagopyrum dibotrys Extract. Fresh plant materials were collected from GAP planting base of Fagopyrum dibotrys in Qujing city, Yunnan province of China, which were identified by expert of Kunming Institute of Botany, Chinese Academy of Sciences. The whole Fagopyrum dibotrys plant was washed and cut into small pieces and dried in shade. $1000 \mathrm{~g}$ fresh plant dried in shade yielded approximately $200 \mathrm{~g}$ powder. The dried powder $100 \mathrm{~g}$ was milled and extracted with $60 \% \mathrm{EtOH}$ at $90^{\circ} \mathrm{C}$ (extract 3 times with $1 \mathrm{~h}$ each time) and the crude extract was eluted with $60 \%$ ethanol and then absorbed and purified by polyamide column chromatography. Ethanol eluted extract was concentrated by a rotary evaporator at $40^{\circ} \mathrm{C}$ and freeze dried and a standard extract of Fagopyrum dibotrys (36 g) was obtained.

2.2. HPLC Analysis of Polyphenols in FDE. The standard extract of Fagopyrum dibotrys was analyzed by high performance liquid column (HPLC/UV). In brief, $25 \mathrm{mg}$ FDE was dissolved in ethanol-0.1\% formic acid (10:90) to final concentration $0.5 \mathrm{mg} / \mathrm{ml}$. An aliquot of the sample solution $10 \mu \mathrm{L}$ was automatically injected into the column for analysis of polyphenol components. The separation was performed on ODS-C18 column $(100 \times 4.6 \mathrm{~mm}, 3 \mu \mathrm{m})$ with gradient elution by the mobile phase A, methanol- $0.1 \%$ formic acid $(10: 90)$, and mobile phase $\mathrm{B}$, methanol-acetonitrile- $0.1 \%$ formic acid $(50: 30: 20)$; the gradient elution processes is $0 \mathrm{~min}(0 \%$ B), $15 \mathrm{~min}(8 \% \mathrm{~B}), 45 \mathrm{~min}(30 \% \mathrm{~B}), 60 \mathrm{~min}(35 \% \mathrm{~B})$, and $75 \mathrm{~min}(100 \% \mathrm{~B})$; the flow rate was $1.0 \mathrm{~mL} / \mathrm{min}$; the column temperature was $40^{\circ} \mathrm{C}$; and the detection wave length was set at $280 \mathrm{~nm}$. This method was accurate in identification and determination of compounds in Fagopyrum extracts and most of chromatogram peaks were identified by HPLCMS/MS.

\subsection{A $\beta$ Disaggregation Assay}

2.3.1. A $\beta$ Preparation. Synthetic A $\beta 42$ was purchased from American Peptide and prepared following the protocols described previously [10]. In brief, the $A \beta 42$ peptide was dissolved in 1,1,1,3,3,3-hexafluoro-2-propanol (HFIP, Sigma) at $1 \mathrm{mg} / \mathrm{ml}$ and was aliquoted in Eppendorf tubes. The HFIP was allowed to evaporate in the fume hood, and the resulting clear peptide film was dried under vacuum overnight.

2.3.2. Thioflavin T Fluorescence Assay. To test the inhibitory effect of FDE on $\mathrm{A} \beta$ aggregation, $1 \mu \mathrm{M}$ A $\beta 42$ monomer was first incubated with a serial gradient of FDE in DMEM at $37^{\circ} \mathrm{C}$ for $10 \mathrm{~d}$ to form $\mathrm{A} \beta$ fibril; the resultants were incubated with $5 \mu \mathrm{M}$ Th T solution. Fluorescence intensity was monitored at an excitation wavelength of $450 \mathrm{~nm}$ and an emission wavelength of $482 \mathrm{~nm}$ by a spectrometer (Turner Biosystems).

2.3.3. Electron Microscopy (EM) Assay. In brief, copper grids were preplaced on the bottom of wells in a 24-well plate where $1 \mu \mathrm{M} \mathrm{A} \beta 42$ monomer was incubated with or without FDE at a concentration gradient for 7 days at $37^{\circ} \mathrm{C}$. Following incubation, the mixtures were stained with $2 \%$ (wt/vol) aqueous phosphotungstic acid for $30 \mathrm{~min}$. The images were collected using a Hitachi7650 TEM equipped with Mega view 3 Digital Camera.

2.3.4. SH-SY5Y Cell Culture and Viability Assay. Human neuroblastoma cell line SH-SY5Y was cultured in RPMI-1640 supplemented with $10 \% \mathrm{FBS}$ at $37^{\circ} \mathrm{C}$. Cells at $60-70 \%$ confluence were treated with $1 \mu \mathrm{M} \mathrm{A} \beta$ with or without FDE $(2.5 \mathrm{mg} / \mathrm{mL}, 5 \mathrm{mg} / \mathrm{mL}$, or $10 \mathrm{mg} / \mathrm{mL})$ for 24 hours, followed by incubation with MTT $(0.5 \mathrm{mg} / \mathrm{ml})$ for $4 \mathrm{~h}$ and $10 \%$ SDS solution for another $15 \mathrm{~min}$ at $37^{\circ} \mathrm{C}$. The optical density at $560 \mathrm{~nm}$ was evaluated by a microplate reader (Turner Biosystems).

2.3.5. Transgenic Mouse Model. APP/PS1 transgenic mice were provided by the South model animal institute, Shanghai. These mice were constructed on a C57BL/6 background and bear a chimeric mouse/human (Mo/Hu) APP695 with mutations linked to familial AD (KM 593/594 NL) and human PS1 carrying the exon-9-deleted variant associated with familial AD (PS1dE9) in one locus under control of a brain- and neuron-specific murine Thy-1 promoter element [11]. Genotypes of the off spring were determined by PCR analysis of tail DNA. Mice were maintained on ad libitum food and water with a $12 \mathrm{~h}$ light/dark cycle.

2.3.6. Diet Treatment. The transgenic mice were randomly divided into 3 groups, each group comprising 12 mice, male $:$ female $=1: 1$. The FDE (Tg) group were treated with $0.65 \%$ FDE mixed food; the dosage $(0.103 \mathrm{mg} / \mathrm{kg} / \mathrm{d})$ used in the current study was based on clinical data. Control (Tg) and another age and sex matched wild-type mice group were fed with standard commercial food (Beijing Keao Xieli Feed Company, Beijing, China). From 3 months old, all the mice were fed the above diets for another 9 months. Food consumption and animal body weight were detected every 3 months during treatment period.

In this study, all experiments were performed in accordance with the European Communities Council Directive (2010/63/UE) and NIH for the Care and Use of Laboratory Animals. The study had been approved by the Committee for Animal Experiments and Ethics at the Kunming Medical University.

\section{AD Type Pathology and Bioanalysis}

3.1. Tissue Sampling. After 9 months of treatment, the mice were anesthetized with $10 \%$ chloral hydrate and the blood was collected from the eyeball for biochemical detection. Next, the brain was perfused with $50 \mathrm{ml}$ chilled standard saline solution and was removed and bisected in the midsagittal plane. The left brain hemisphere was fixed in $4 \%$ paraformaldehyde ( $\mathrm{pH} 7.4$ ) for $24 \mathrm{~h}$ and incubated for another $48 \mathrm{~h}$ in $30 \%$ sucrose for subsequent cryoprotection. Coronal sections of the brain were cut at $35 \mu \mathrm{m}$ thickness $\mathrm{d}$ with 
a cryosectioning microtome and stored at $4^{\circ} \mathrm{C}$ in PBS containing $40 \%$ glycol until use. The right brain was snap frozen in liquid nitrogen and stored at $-80^{\circ} \mathrm{C}$ for future biochemical analysis.

3.2. Pathological Staining and Image Analysis. A series of five equally spaced tissue sections $(\sim 1.3 \mathrm{~mm}$ apart) were randomly selected and stained using free-floating immunohistochemistry (Biotin-conjugated mouse anti-A $\beta$ antibody 6E10, Serotec) and Congo red for total $A \beta$, activated microglia (rat monoclonal anti-CD45 Chemicon, USA), and astrocyte (rabbit polyclonal antiglial fibrillary acidic protein, Dako, Denmark), respectively. Sections were incubated overnight with primary antibodies at $4^{\circ} \mathrm{C}$, further developed with biotinylated secondary antibodies, and visualized with diaminobenzidine (Slide Kit Chemical international, Inc. Millipore).

For the compact $\mathrm{A} \beta$ plaque staining, a series of sections was mounted and stained with Congo red. In brief, the sections were treated with working sodium chloride solution (containing sodium chloride saturated in $80 \%$ alcohol and $0.01 \%$ sodium hydroxide) at room temperature for $30 \mathrm{~min}$, then placed directly into working Congo red solution (containing saturated Congo red in working sodium chloride solution) for $1 \mathrm{~h}$, and dehydrated rapidly in absolute alcohol.

The region of neocortex and hippocampus manually was selected for quantification of total $\mathrm{A} \beta$ plaques and microgliosis. The images were acquired in the same session and collected at $4 \mathrm{x}$ magnification using constant bulb temperature and exposure (Olympus DP73), yielding the area fraction of the total positive staining against the area of tissue analyzed; the average number of deposits was calculated per each brain area; all image analyses were developed in a blind manner.

3.3. Quantification of $A \beta$ Peptide Levels by ELISA. ELISA analysis of the brain $\mathrm{A} \beta$ was processed as described previously [12]. Briefly, frozen brain was homogenized and sonicated in TBS containing protease inhibitors. Homogenates were centrifuged at $100,000 \times g$ for $1 \mathrm{~h}$ at $4^{\circ} \mathrm{C}$, and the resultant supernatant was collected, representing the TBS-soluble fraction (A $\beta$-TBS). The resultant pellet was suspended and sonicated in water containing $2 \%$ SDS and protease inhibitors. The SDS solubilized homogenates were centrifuged at $100,000 \times g$ for $1 \mathrm{~h}$ at $4^{\circ} \mathrm{C}$, and the resultant supernatant was collected, representing the SDS-soluble fraction (A $\beta$-SDS). The resultant pellet was then extracted in $70 \%$ formic acid (FA) and centrifuged, and the resultant supernatant was collected, representing the SDS-insoluble fraction $(\mathrm{A} \beta$-FA). Before ELISA assay, formic acid extracts were neutralized by $1: 20$ dilution into $1 \mathrm{M}$ Tris phosphate buffer, $\mathrm{pH} 11$, and then diluted in sample buffer. Concentrations of $\mathrm{A} \beta 40$ and of $\mathrm{A} \beta 42$ in brain extract and serum were quantitatively measured by ELISA following the manufacturer's instructions (ELISA kits, Millipore).

3.4. Quantification of IL-1 $\beta, T N F-\alpha$, and IFN- $\gamma$ in the Mouse Plasma by ELISA. IL- $1 \beta$, TNF- $\alpha$, and IFN- $\gamma$ in the plasma of

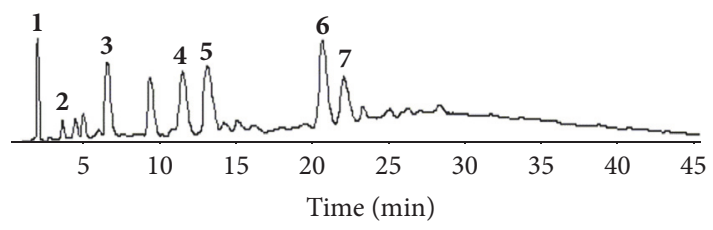

FIgURE 1: The HPLC/UV chromatograms of Fagopyrum dibotrys extract. Peaks: 1. gallic acid; 2. protocatechuic acid; 3 . catechin; 4. dimer gallic acid ester; 5 epicatechin; 6. trimer gallic acid ester; 7. epicatechin gallate.

mice were measured using ELISA kits as per manufacturer's instructions (ELISA kits, eBioscience).

3.5. Assessment of Toxicity of FDE. Total bilirubin, alanine aminotransferase (ALT), and aspartate aminotransferase (AST) were analyzed by Analytical Biochemical Laboratory of First Affiliated Hospital of Kunming Medical University.

\section{Statistical Analysis}

Results were generally presented as mean \pm standard error of the mean (SEM). Statistical analysis was performed using one-way ANOVA followed by post hoc Student's test where appropriate; $p<0.05$ were considered statistically significant. Statistical analysis was performed using SPSS for Windows version 20.0 (SPSS Inc.).

\section{Results}

5.1. HPLC Analysis of Polyphenol Compounds in FDE. The presence of polyphenols in the extracts was confirmed by identifying characteristic spectral features and comparison with standard compounds (>95\% purity by HPLC, Shanghai Tauto Biotech Co., Ltd.). The use of reversed phase high performance liquid chromatography allowed the identification of 7 phenolic constituents; there were gallic acid, protocatechin acid, catechin, dimer gallic acid ester and epicatechin, trimer gallic acid ester, and epicatechin gallate (Figure 1).

\subsection{Effects of the FDE on the Fibrillation and Cytotoxicity of $A \beta$} Peptide. To investigate the effects of FDE on the fibrillation and cytotoxicity of $\mathrm{A} \beta$ protein, the inhibitory effects of FDE on $A \beta 1-42$ fibril formation were determined by using thioflavin $\mathrm{T}$ fluorescence (Th-T) and Electron Microscopy (EM); the protective effects against cytotoxicity induced by A $\beta 1-42$ in SH-SY5Y cells were evaluated by MTT assay. The data from Th-T fluorescence assay showed that FDE had a dose-dependent effect on disaggregation of preformed A $\beta 1-42$ fibril (ANOVA, $F=10.762, p<0.001$, Figure $2(\mathrm{c})$ ), it also reduced the neurotoxicity of $A \beta 1-42$ on the cultured SH-SY5Y cells (Figures 3(a) and 3(b), $p<0.05$ ).

The morphologies of the assemblies present following $\mathrm{A} \beta$ incubations with or without FDE were examined using Electron Microscopy (EM). When A $\beta 42$ was incubated under fibril-forming conditions, different morphology of amyloid 


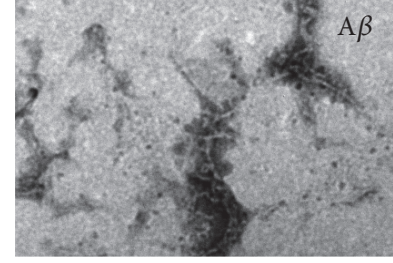

(a)

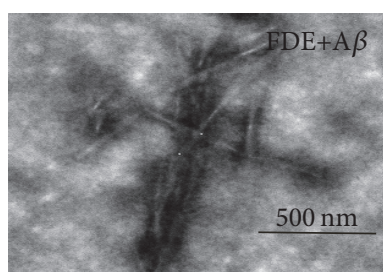

(b)

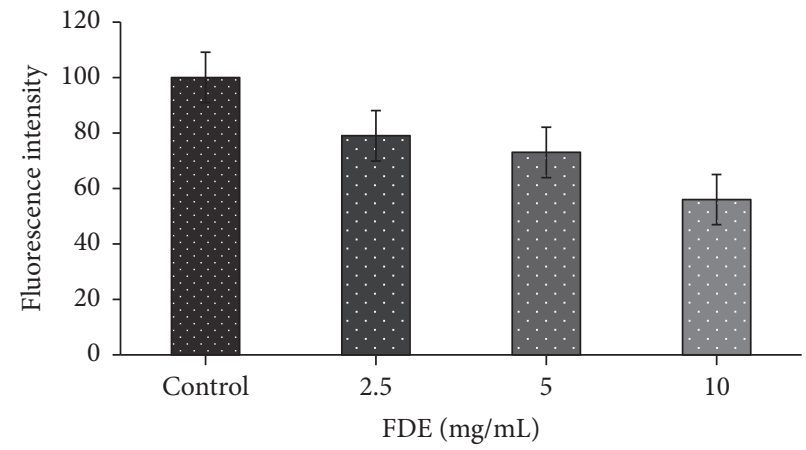

(c)

Figure 2: FDE disaggregate of $\mathrm{A} \beta$ fibrils. (a) Preformed $\mathrm{A} \beta 1 \mu \mathrm{M}$ was incubated alone at $37^{\circ} \mathrm{C} 5 \mathrm{~d}$. (b) $\mathrm{A} \beta$ with $\mathrm{FDE}$ at $37^{\circ} \mathrm{C}$ for an additional 3 d. Scale bar, $500 \mathrm{~nm}$. (c) Th.T assays for effect of FDE on disaggregation of preformed A $\beta$ fibrils $(n=3, p<0.05)$.

fibrils such as nonbranching fibrils, twisted long fibrils, and some small aggregates mixed with fibrils could be observed (Figure 2(a)). Conversely, when preformed $\mathrm{A} \beta$ fibrils were further incubated with FDE for an additional 3 days (Figure $2(\mathrm{~b}))$, there were hardly any long fibrils on squares of grids.

These data indicate that FDE can effectively inhibit A $\beta 1-42$ fibril formation and significantly lower the neurotoxicity on the cultured SH-SY5Y cells, suggesting potential effect of the FDE on $\mathrm{A} \beta$ clearance.

5.3. FDE Is Well Tolerated in APP/PS1 Transgenic Mice. During treatment period, we did not observe any animal death occurring and any differences in animal viability general activities among the groups. It is important to note that the long-term daily consumption FDE diet for 9 months in APP/PS1 transgenic mice did not significantly influence animal body weight and liver function (Figures 4(a) and 4(b), $p>0.05$, the serum level was too low to be detected). The FDE was well tolerated in AD mice.

5.4. FDE Attenuates $A \beta$-Related Pathologies. In order to know $\mathrm{A} \beta$ deposition in the brain after FDE treatment, the $\mathrm{AD}$ brain sections were stained with anti-A $\beta$ antibody $6 \mathrm{E} 10$ and Gongo red; a histological dye is commonly used to detect fibrillar $\mathrm{A} \beta$ plaques [13]. A $\beta$ plaques were observed primarily in the neocortical and hippocampal areas of the brain, as observed in Figures 5(a), 5(b), 5(d), and 5(e).

The total number of $\mathrm{A} \beta$ plaques stained by immunohistochemistry and Congo red in the brain was, respectively, reduced by $57 \%$ and $49 \%$ (Figures 5(c) and 5(f)); FDE treatment group had a significantly lower $\mathrm{A} \beta$ plaques numbers than control group fed with normal diet (ANOVA, $F=5.420$, $p<0.05$, and ANOVA, $F=6.480, p<0.05)$. We further examined the brain and plasma $A \beta$ levels by ELISA tests; the levels of total $\mathrm{A} \beta 40$ and $\mathrm{A} \beta 42$ in SDS and FA fractions of brain homogenates of FDE treatment group were significantly declined compared to control group (Tg) (ANOVA, $F=$ 71.044, $p<0.05$; ANOVA, $F=15.481, p<0.001$; ANOVA, $F=8.425, p<0.05)$; the levels of $\mathrm{A} \beta 40$ and $\mathrm{A} \beta 42$ in formic acid (FA) also showed significant decline (Figures 6(b) and $6(c), p<0.05)$. In addition, the total $A \beta$ level in plasma of FDE treatment group obviously reduced by 55\% (Figure $6(\mathrm{~d})$ ), which correlated with the change tendency of total brain A $\beta$ levels (Pearson $r=0.883, p<0.05$ ).

Activated microglia are associated with the progression of Alzheimer's disease (AD); therefore microglia are key targets for therapeutic intervention [14]. Here, we examined the activated microglia with rat monoclonal anti-CD45 in the neocortical and hippocampal areas of the brain; the levels of activated microglia in FDE treatment group were obviously decreased compared to the transgenic mice fed with normal diet $(11 \pm 3$ versus $30 \pm 4.5, p<0.001$, Figure $7(\mathrm{c}))$. Moreover, we measured the levels of IL- $1 \beta$, TNF- $\alpha$, and IFN- $\gamma$ in the plasma; ELISA assay showed that the level of proinflammatory cytokine TNF- $\alpha$ in serum in the FDE treatment group was lower than APP/PS1 control group $(36.7 \pm 4.3$ versus $20 \pm 2.7, p<0.05$, Figure $7(d))$, but no significantly lower levels of IL- $\beta$ and IFN- $\gamma$ were observed in FDE treatment group. In Addition, characteristic blue haemosiderin-positive profiles on the stained brain slices were observed. The microhaemorrhage rates in the FDE group were detected at a rate of $24.5 \pm 3.6$ per hemibrain $(p<0.05)$ which was lower than Control group fed with normal diet (38.0 \pm 6 per hemi-brain, $p<0.05$, Figure 8$)$. 


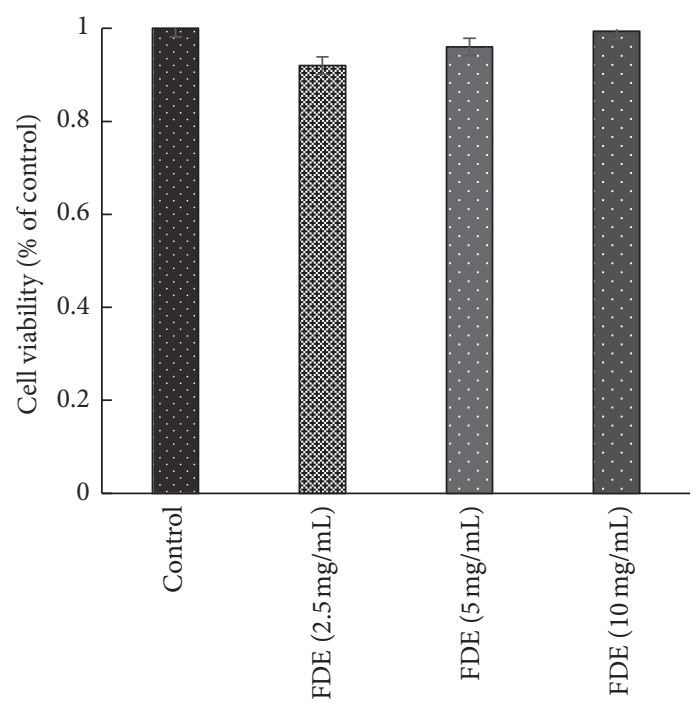

(a)

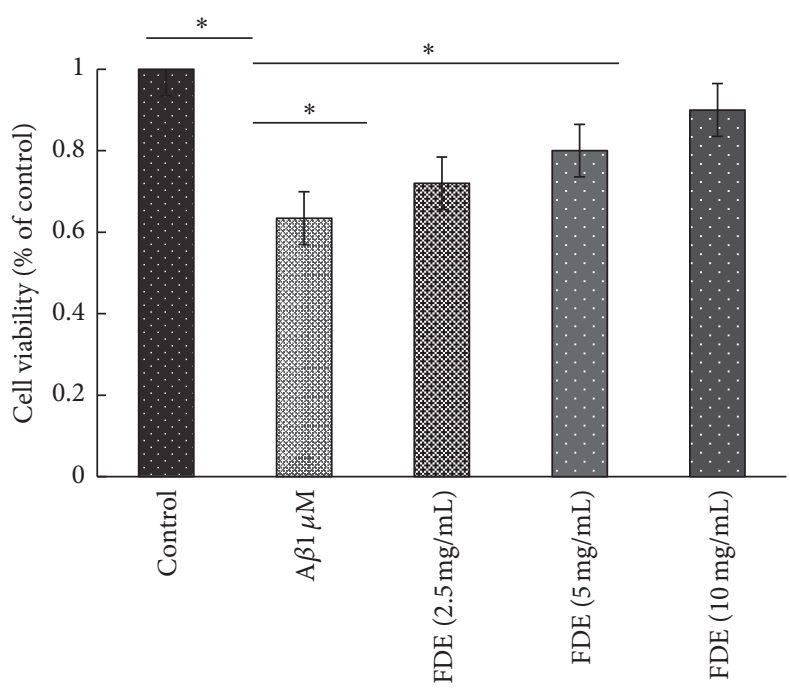

(b)

FIGURE 3: FDE attenuates the toxic effect of A $\beta 42$ in SH-SY5Y cells. MTT assay of cell viability of SH-SY5Y cells treated with (a) various doses of FDE for $24 \mathrm{~h}\left({ }^{*} p>0.05\right)$ and (b) $1 \mu \mathrm{M} \mathrm{A} \beta 42$ with various doses of $\mathrm{FDE}\left({ }^{*} p<0.05\right)$.

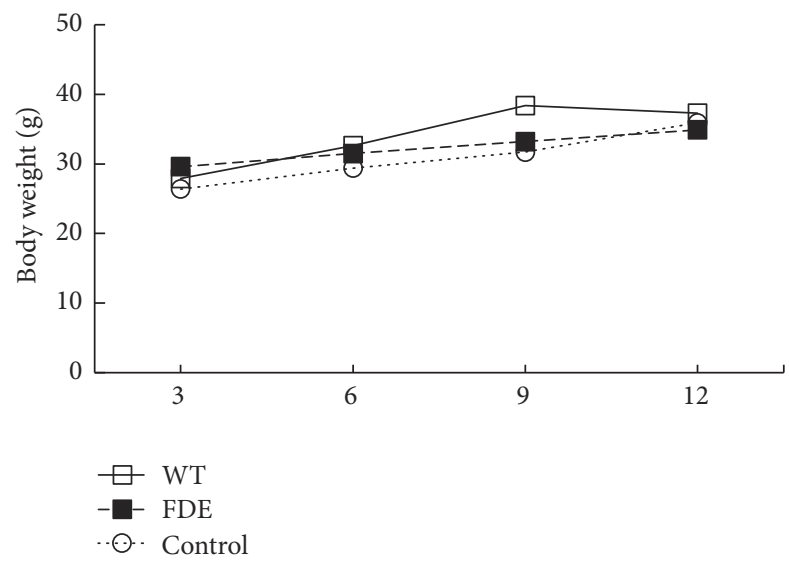

(a)

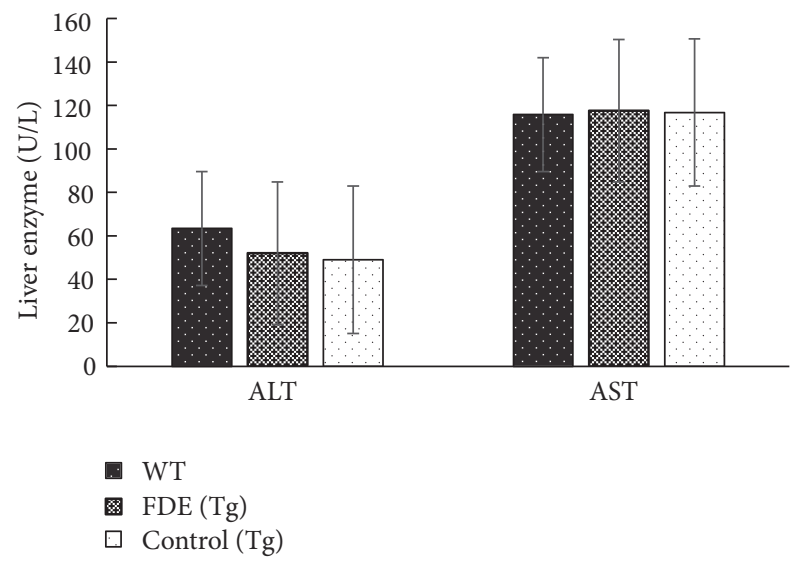

(b)

FIGURE 4: FDE is well tolerated in APP/PS1 transgenic mice. (a) Body weight was monitored at 3, 6, 9, and 12 months of age. (b) Serum levels of ALT and AST $(p>0.05)$. Points and bar graphs represent group mean $( \pm$ SEM).

\section{Discussion}

The present results showed the neuroprotective ability of FDE on AD-like symptoms in transgenic mice. Besides, the antiamyloidogenic effects of FDE in vitro were detected in this study. To our knowledge, this is the first time to report that polyphenol extract of Fagopyrum dibotrys has preventive effects on an animal model of AD pathology.

Our data demonstrate that FDE cleared A $\beta$ deposits that appeared in the brain and decreased $\mathrm{A} \beta$ from the plasma, reduced microhaemorrhage, decreased reactive microglia in brain, and reduced the TNF- $\alpha$ level in serum. But, we did not observe FDE reverse deficits in motor function and spatial working memory in the Morris water maze test (result is not shown).

Other putative agents tested for enhancement of cognition in animal models can improve memory. For example, blueberry appears to have a pronounced effect on short term memory and has been shown to improve long-term reference memory following 7 weeks of supplementation [15]; the flavonoid-rich plant extract of Ginkgo biloba has also been shown to induce positive effects on memory, learning, and concentration [16]. The differences in effects on memory between these results and those in the present manuscript 


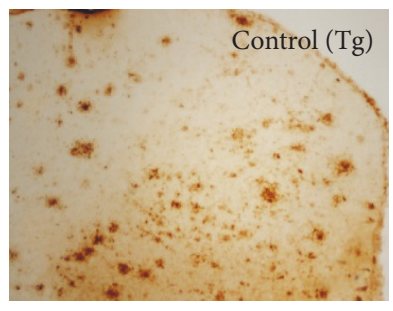

(a)

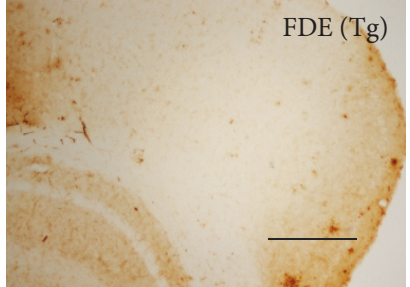

(b)

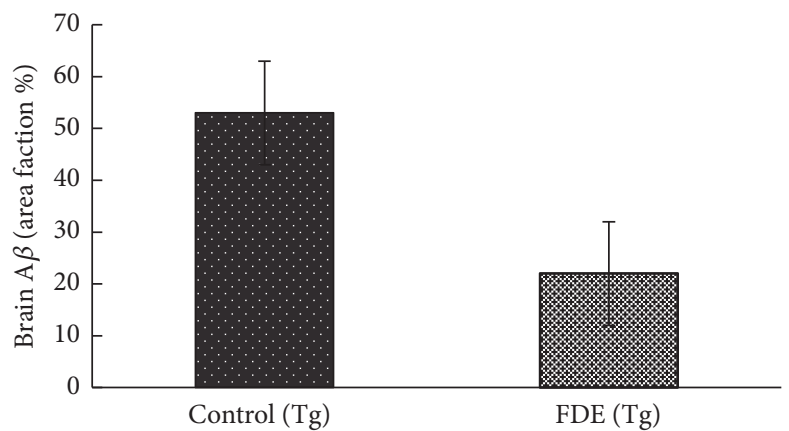

(c)

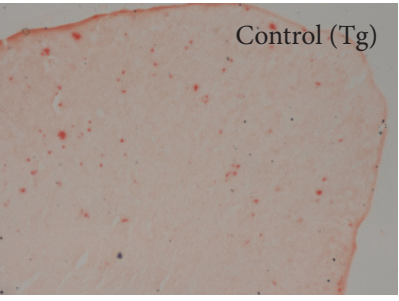

(d)

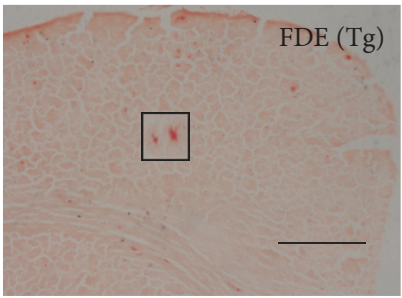

(e)

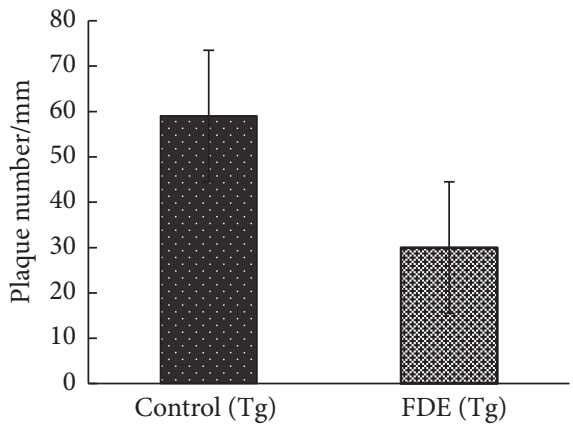

(f)

FIgURE 5: A plaque burden in the brain of mice. (a-b) IHC-positive A $\beta$ plaques in neocortex of 9-month-old mice. (c) Comparison of IHCpositive $\mathrm{A} \beta$ plaque density in neocortex of 9-month-old mice. (d-e) Congo red-positive $\mathrm{A} \beta$ plaques in neocortex of 9-month-old mice. (f) Comparison of Congo red-positive $\mathrm{A} \beta$ plaque density in neocortex of 9 -month-old animals. Denote $p<0.05$ versus control group.

may be attributed to different strains of mice tested or different chemical structures of the compounds tested. Hence, the beneficial effects and mechanisms of polyphenols on memory deficits caused by $\mathrm{A} \beta$ need further research [17].

Amyloid $\beta(\mathrm{A} \beta)$ is toxic to neurons and is associated with multiple pathogenic cascades. Inhibition of $\mathrm{A} \beta$ aggregation or disaggregation of $\mathrm{A} \beta$ fibrils are important strategies for prevention and treatment of $\mathrm{AD}$. In this study, we found that FDE significantly attenuated $\mathrm{A} \beta 42$ fibril-induced toxicity on SH-SY5Y cells, inhibited A $\beta 1-42$ fibril formation in all tested concentrations, consistent with the effects of other polyphenols contained in grape seed extract, wine, bilberry, and blackcurrant, which have been shown to destabilize the preformed $\mathrm{A} \beta$ fibrils in vitro, and exhibited antiamyloidogenic activity [18].

New research suggests that pathological accumulation of $\mathrm{A} \beta$ is a key factor that drives neuroinflammatory responses in Alzheimer's disease; these $\mathrm{A} \beta$ aggregates bind to cell-surface 

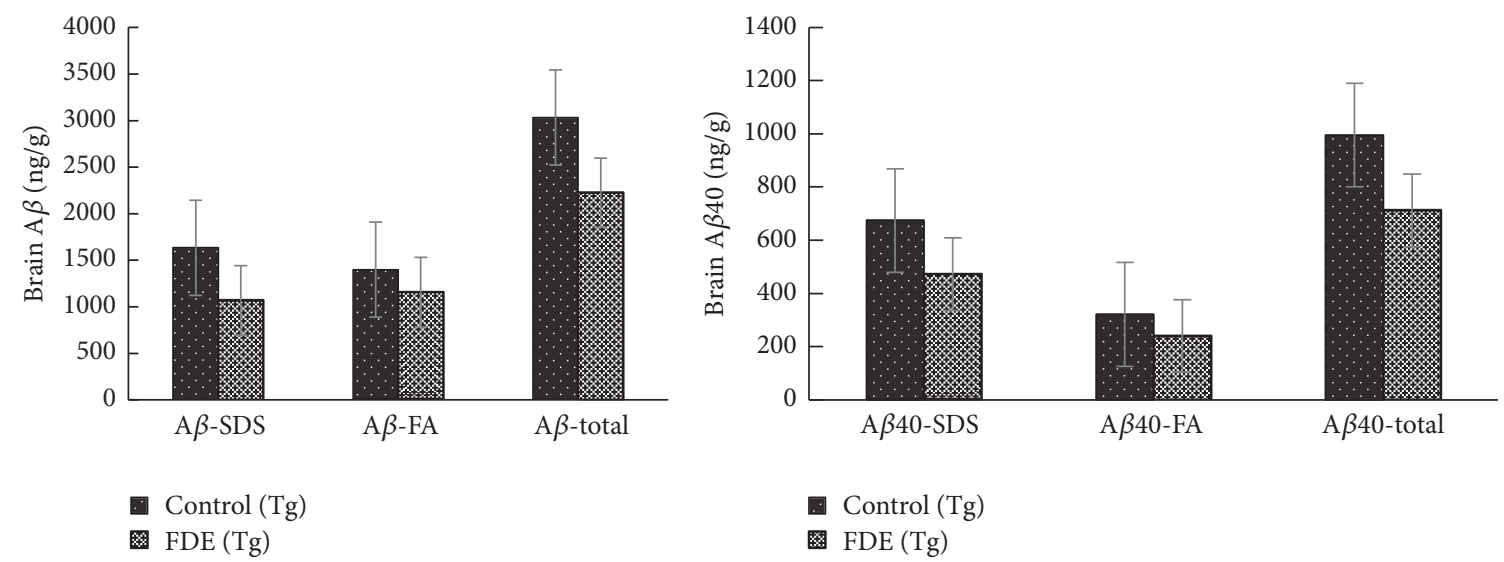

(a)
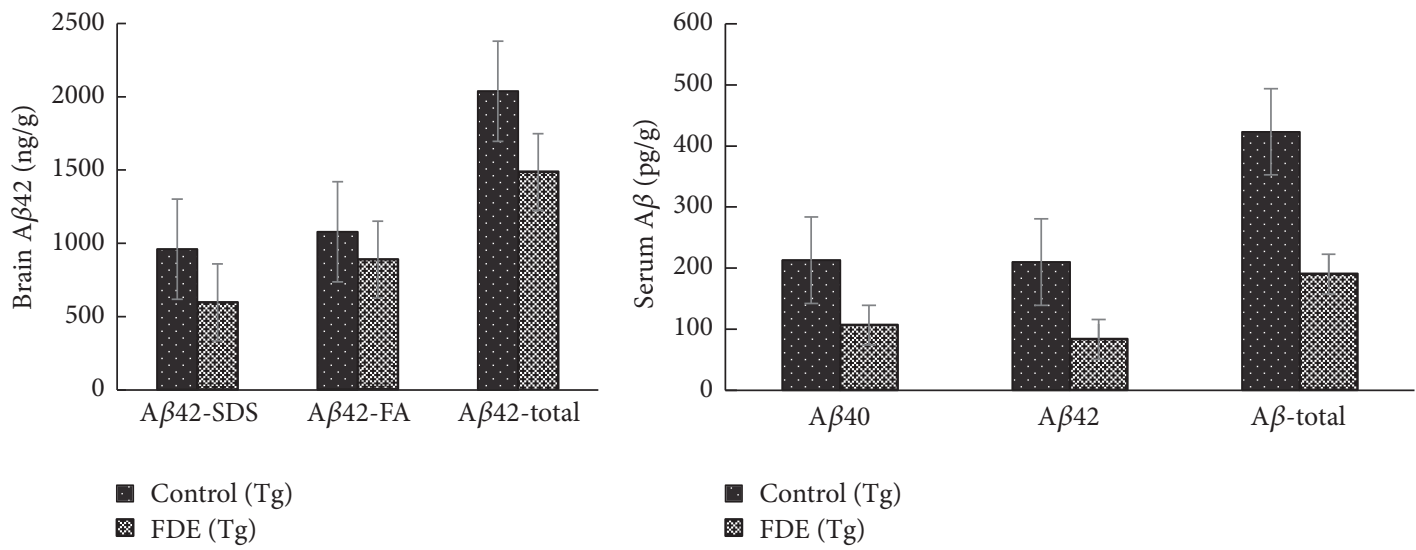

(c)

(d)

FIGURE 6: Effects of FDE consumption on $A \beta$ levels in the brain and serum of APP/PS1 transgenic mice. (a) Comparison of total A $\beta$, A $\beta$ in SDS fraction (A $\beta$-SDS), and $\mathrm{A} \beta$ in formic acid fraction (A $\beta$-FA) among groups. (b) Comparison of total $\mathrm{A} \beta 40, \mathrm{~A} \beta 40-\mathrm{SDS}$, and $\mathrm{A} \beta$ 40-FA. (c) Comparison of total and A $\beta 42-F A$. (d) Comparison of total, A $\beta 42, \mathrm{~A} \beta 42$-SDS A $\beta 40$, and A $\beta 42$ in serum. Denote $p<0.05$ or $p<0.01$ versus APP/PS1 transgenic mice fed with control diet. Scale bar, $1 \mathrm{~mm}$.

receptors on microglia, inducing an inflammatory activation that results in the secretion of proinflammatory cytokines [19], including TNF- $\alpha$, interleukin $1 \beta$, and IFN- $\gamma$. Overexpression of inflammatory cytokines has been shown to increase tau pathology [20]. Our data showed the plasma level of TNF- $\alpha$ and reactive microglia are decreased after FDE treatment, indicating that the FDE can modulate neuroinflammation and alleviate harmful effects formed under pathological conditions. Cerebral amyloid angiopathy (CAA) has been recognized as one of the morphologic hallmarks of Alzheimer disease (AD), resulting from deposition of $\beta$ amyloid in the media and adventitia of small arteries and capillaries of the leptomeninges and cerebral cortex, which is associated with cerebral microbleeds and white matter hyperintensities [21]. The present study found that FDE is beneficial in ameliorating cerebral microbleeds, possibly a result of clearance of the 12 amyloid- $\beta$ peptide from the brain. This finding may suggest FDE's potential as preventive agent for cerebral amyloid angiopathy (CAA).

In conclusion, the present study showed that the oral administration of FDE prevented the development of $\mathrm{AD}$ pathology in an animal model by targeting multiple pathways. It provides a novel suggestion that FDE might show promise in the prevention or treatment of $\mathrm{AD}$.

\section{Conflicts of Interest}

The authors declare that they have no conflicts of interest.

\section{Authors' Contributions}

Chen Liang and Jian-Ping Yuan contributed equally to this work.

\section{Acknowledgments}

This work was supported by grants from National Natural Science Foundation (81441136) and "Innovation Team Development program of the Ministry of Education of China," the State Key Laboratory of Stem Cell and Regenerative Medicine of Yunnan Province. 


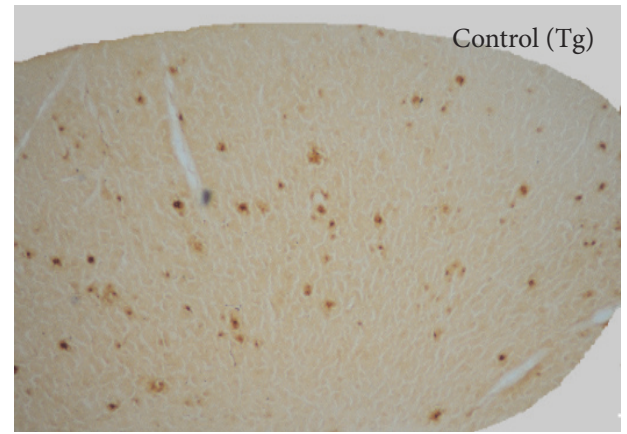

(a)

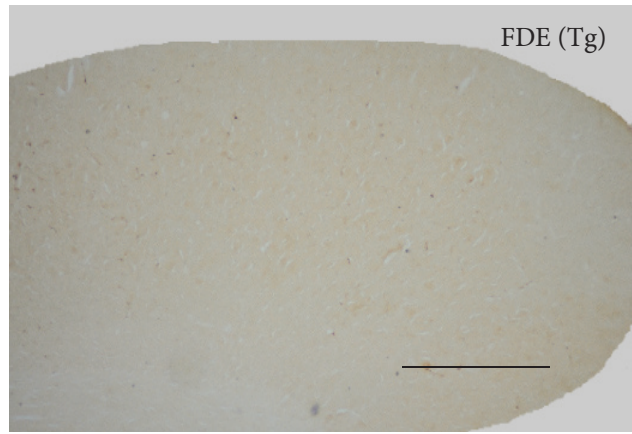

(b)
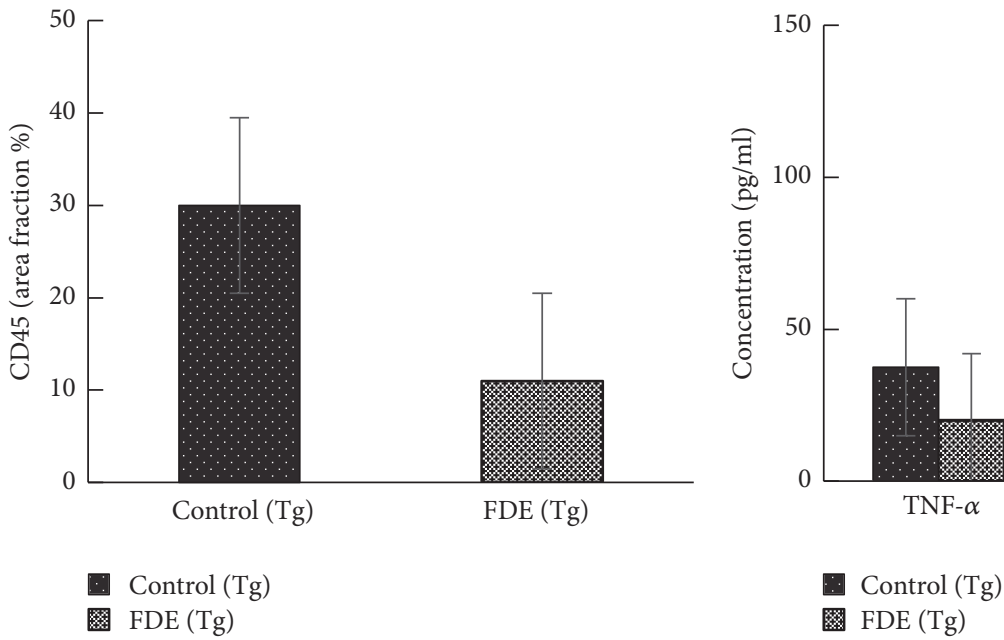

(c)

(d)

FIGURE 7: FDE attenuates inflammation in APP/PS1 transgenic mice. (a-c) Representative images of staining in APP/PS1. No obvious microgliosis was observed in the brain of FDE treatment transgenic mice. (c) Comparison of CD45 area fraction in neocortex among groups. (d) Quantification of IL-1 $\beta$, IL-6, TNF- $\alpha$, and IFN- $\gamma$ in plasma. Denote $p<0.05$ or $p<0.01$ versus control (Tg) mice, as determined by one-way ANOVA. Scale bar, $1 \mathrm{~mm}$.

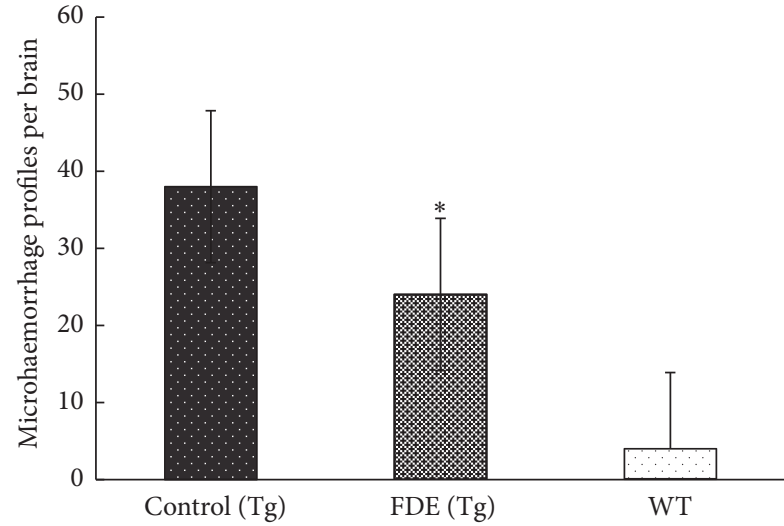

(a)

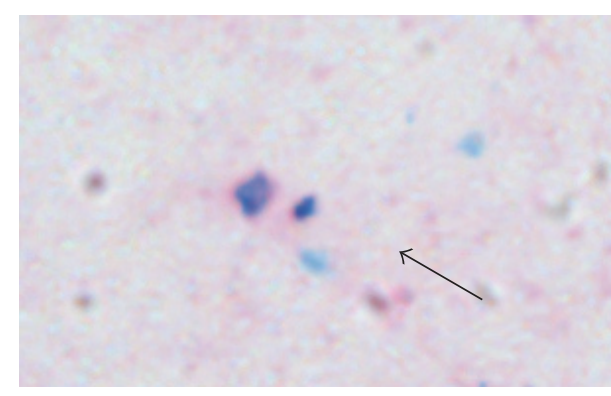

(b)

FIGURE 8: Effects of FDE treatment on microhaemorrhage profiles in the brain. (a) Comparison of microhaemorrhage profiles; denote ${ }^{*} p<$ 0.05 versus wild-type littermate fed with control diet. (b) An example of microhaemorrhage profile (solid arrow) observed in neocortex. 


\section{References}

[1] H. W. Querfurth and F. M. LaFerla, "Alzheimer's disease," The New England Journal of Medicine, vol. 362, no. 4, pp. 329-344, 2010.

[2] M. T. Heneka and M. K. O'Banion, "Inflammatory processes in Alzheimer's disease," Journal of Neuroimmunology, vol. 184, no. 1-2, pp. 69-91, 2007.

[3] A. R. Li, "Fagopyrum," in Flora of China, vol. 25, Science Press and the Missouri Botanical Garden Press, Beijing, China, 2003.

[4] N. P. Manandhar and S. Manandhar, Plants and People of Nepal, Timber Press, London, UK, 2002.

[5] Editorial Board of Zhong Hua Ben Cao of State Administration of Traditional Chinese Medicine, Zhong Huaen Cao, vol. 2, Shanghai Science and Technology Press, Shanghai, China, 1999.

[6] T. Mori, N. Koyama, M.-V. Guillot-Sestier, J. Tan, and T. Town, "Ferulic acid is a nutraceutical $\beta$-secretase modulator that improves behavioral impairment and alzheimer-like pathology in transgenic mice," PLoS ONE, vol. 8, no. 2, Article ID e55774, 16 pages, 2013.

[7] Y.-Q. Zeng, Y.-J. Wang, and X.-F. Zhou, "Effects of (-)epicatechin on the pathology of APP/PS1 transgenic mice," Frontiers in Neurology, vol. 5, article 69, 2014.

[8] G. M. Pasinetti, J. Wang, L. Ho, W. Zhao, and L. Dubner, "Roles of resveratrol and other grape-derived polyphenols in Alzheimer's disease prevention and treatment," Biochimica et Biophysica Acta-Molecular Basis of Disease, vol. 1852, no. 6, pp. 12021208, 2014.

[9] K. B. Pandey and S. I. Rizvi, "Plant polyphenols as dietary antioxidants in human health and disease," Oxidative Medicine and Cellular Longevity, vol. 2, no. 5, pp. 270-278, 2009.

[10] K. N. Dahlgren, A. M. Manelli, W. Blaine Stine Jr., L. K. Baker, G. A. Krafft, and M. J. Ladu, "Oligomeric and fibrillar species of amyloid- $\beta$ peptides differentially affect neuronal viability," Journal of Biological Chemistry, vol. 277, no. 35, pp. 3204632053, 2002.

[11] J. L. Jankowsky, H. H. Slunt, T. Ratovitski, N. A. Jenkins, N. G. Copeland, and D. R. Borchelt, "Co-expression of multiple transgenes in mouse CNS: a comparison of strategies," Biomolecular Engineering, vol. 17, no. 6, pp. 157-165, 2001.

[12] Y.-J. Wang, X. Wang, J.-J. Lu et al., "p75NTR regulates $A \beta$ deposition by increasing $A \beta$ production but inhibiting $A \beta$ aggregation with its extracellular domain," Journal of Neuroscience, vol. 31, no. 6, pp. 2292-2304, 2011.

[13] P. Frid, S. V. Anisimov, and N. Popovic, "Congo red and protein aggregation in neurodegenerative diseases," Brain Research Reviews, vol. 53, no. 1, pp. 135-160, 2007.

[14] P. L. McGeer and E. G. McGeer, "Targeting microglia for the treatment of Alzheimer's disease," Expert Opinion on Therapeutic Targets, vol. 19, no. 4, pp. 497-506, 2015.

[15] D. Vauzour, K. Vafeiadou, A. Rodriguez-Mateos, C. Rendeiro, and J. P. E. Spencer, "The neuroprotective potential of flavonoids: a multiplicity of effects," Genes and Nutrition, vol. 3, no. 3-4, pp. 115-126, 2008.

[16] C. Ude, M. Schubert-Zsilavecz, and M. Wurglics, "Ginkgo biloba extracts: a review of the pharmacokinetics of the active ingredients," Clinical Pharmacokinetics, vol. 52, no. 9, pp. 727-749, 2013.

[17] D. Vauzour, "Dietary polyphenols as modulators of brain functions: biological actions and molecular mechanisms underpinning their beneficial effects," Oxidative Medicine and Cellular Longevity, vol. 2012, Article ID 914273, 16 pages, 2012.

[18] T. Hamaguchi, K. Ono, A. Murase, and M. Yamada, "Phenolic compounds prevent Alzheimer's pathology through different effects on the amyloid- $\beta$ aggregation pathway," American Journal of Pathology, vol. 175, no. 6, pp. 2557-2565, 2009.

[19] M. T. Heneka, M. J. Carson, J. El Khoury et al., "Neuroinflammation in Alzheimer's disease," The Lancet Neurology, vol. 14, no. 4, pp. 388-405, 2015.

[20] S. Ghosh, M. D. Wu, S. S. Shaftel et al., "Sustained interleukin$1 \beta$ overexpression exacerbates tau pathology despite reduced amyloid burden in an alzheimer's mouse model," Journal of Neuroscience, vol. 33, no. 11, pp. 5053-5064, 2013.

[21] A. Viswanathan and S. M. Greenberg, "Cerebral amyloid angiopathy in the elderly," Annals of Neurology, vol. 70, no. 6, pp. 871880,2011 


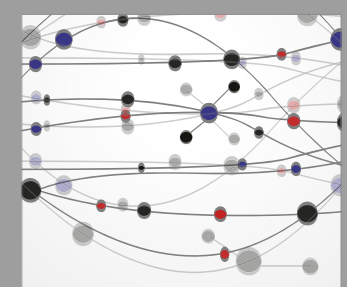

The Scientific World Journal
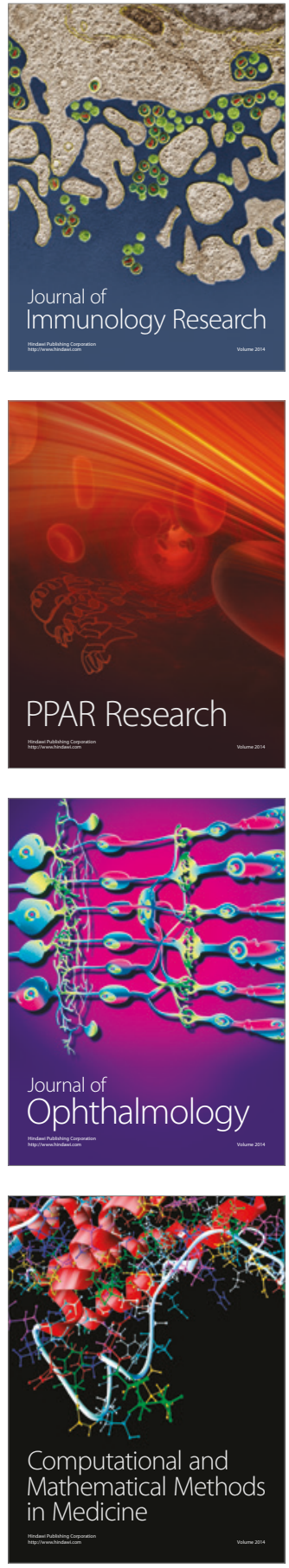

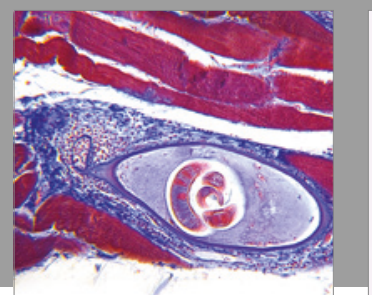

Gastroenterology Research and Practice
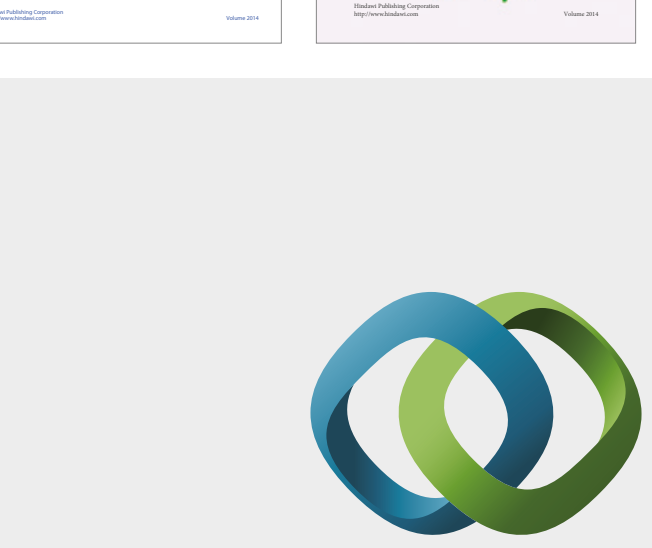

\section{Hindawi}

Submit your manuscripts at

https://www.hindawi.com
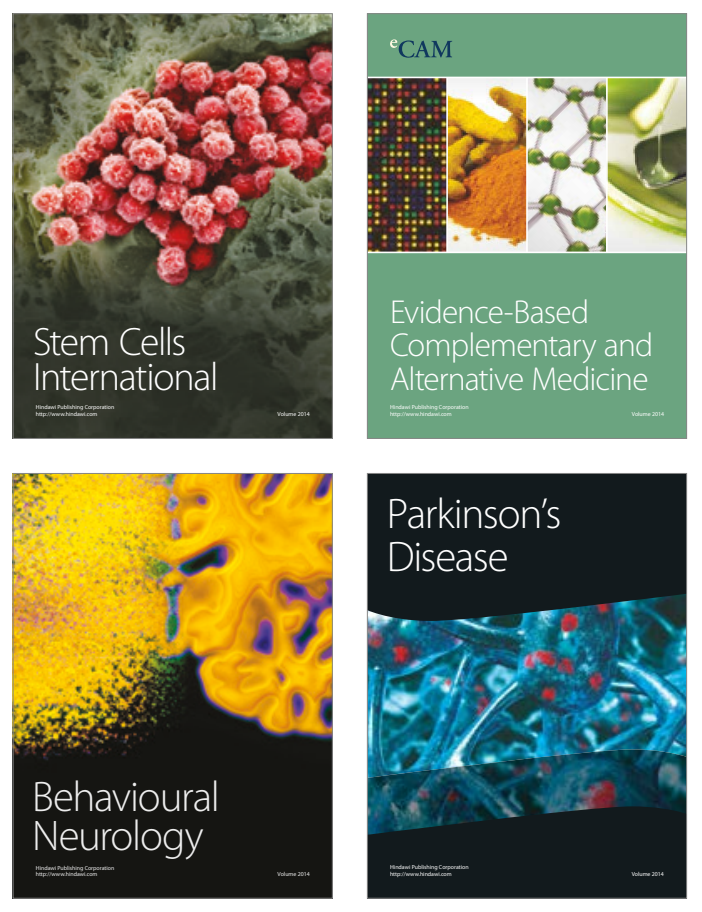
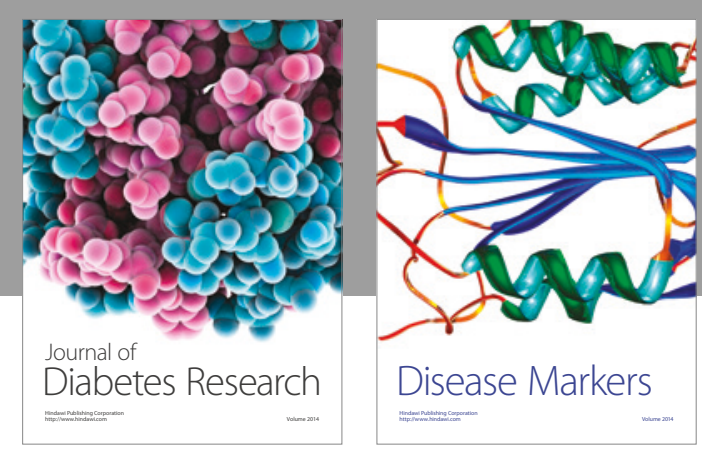

Disease Markers
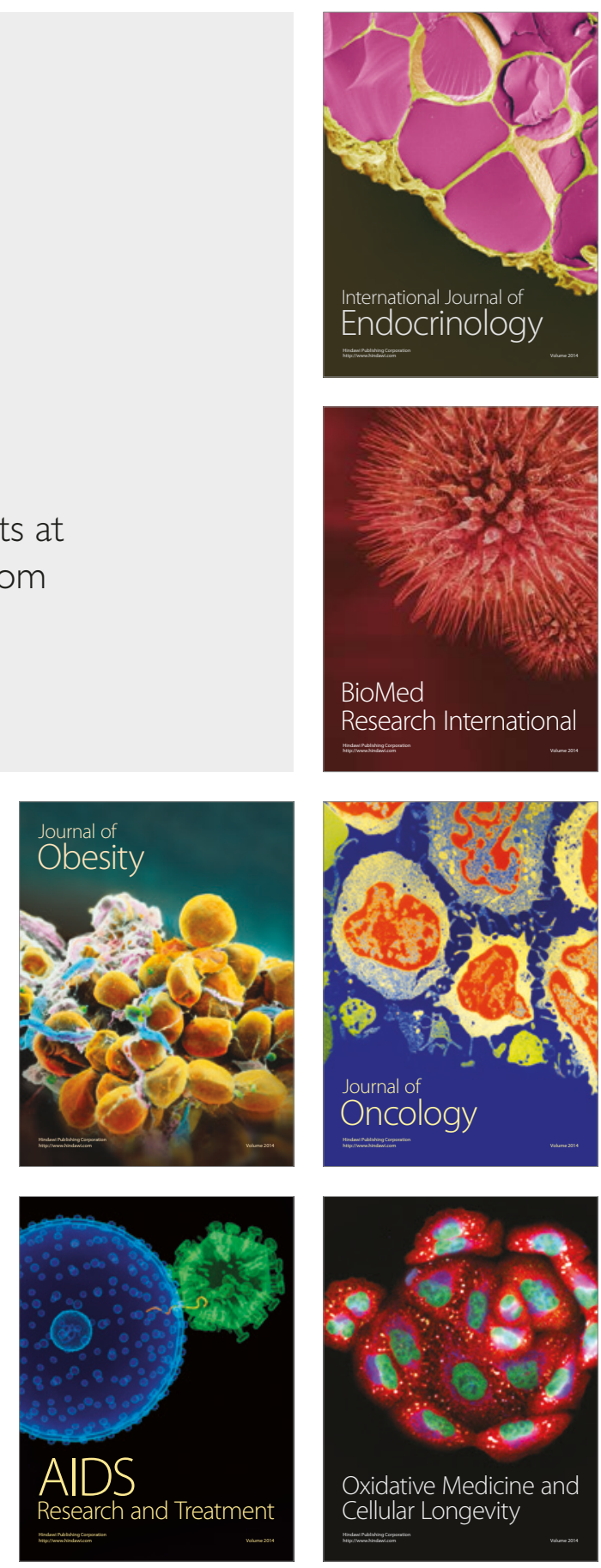